\title{
Chinese ski sports tourism development research under grey model
}

\author{
Bing Zhang ${ }^{1, a}$ and Kunling Qin ${ }^{2}$ \\ ${ }^{1}$ Institute of Physical Education, Huanggang Normal University, Huangzhou 438000, China \\ ${ }^{2}$ Yidu Gaobazhou Middle School, Yidu 443300, China
}

\begin{abstract}
In recent years, drift, ski, golf and other series of sports tourism modes have gradually organized. As people's request on spiritual life increases, sports tourism has been developed to a certain degree. The paper takes ski sports tourism as an example to study on Chinese sports tourism future status. Relying on grey model, it proceeds with ultimate ratio verification on original data, and adjusts original data, thereupon, establishes relationships between sports tourism development status and time. Sports tourism development status is reflected by ski resorts amount and number of people that participates in ski these two aspects, therefore establishes two kinds of mathematical models.
\end{abstract}

\section{Introduction}

As people's living standard improves, sports tourism as middle and high-end products, it appears in the public life. Its appearance has changed sports industrial structure to a certain degree, let Chinese sports industry to be further developed. And meanwhile, it drives Chinese economic development.

In 2013, Zhao Jin-Ling in the article "Chinese high-end sports tourism theory and empirical research", he comprehensively used multiple research methods, analyzed Chinese high-end sports tourism development status from multiple perspectives. The article pointed out that since sports tourism market became mature, merchants developed high-end sports tourism products to meet consumers' cool demands. The kind of tourism products could be divided into seven kinds, leisure kind, stimulation kind, field operation kind, event kind, study kind, appreciation kind and competitive kind. From the perspective of individual, high-end sports tourism could meet the demand of consumers. From the overall perspective of sports industry, high-end sports tourism could impel sports industry to healthy and rapidly develop. From the perspective of nation, high-end sports tourism could promote nation's image. By far, as far as development status is concerned, Chinese high-end sports tourism still had some problems, chaotic resources development, lagging regulations and laws, lacking of subsequent development trend, employee's poor professional standards. With respect to this, the author pointed out that sports tourism industry needed scientific development strategy, reasonable developing sports tourism resources, perfecting corresponding legislation system, implementing combat confusing by law. And meanwhile, it should focus on professionals' cultivation [1-3].
In 2009, Zhong Chen in the article "Hanzhong city sports tourism resources development mode study", he took Shanxi province's Hanzhong city as an example, on the basis of analyzing its geographic resources and present tourism resources development, from sports tourism resources connotation, development contents and principles that development process should adhere these three aspects, it explored sports tourism resources development modes. The author comprehensively applied multiple research methods, on the premise of referencing lots of documents, it analyzed Hanzhong city sports tourism development status. The author pointed out that sports resources development should follow sustainable development, optimal efficiency, standing out features, overall planning, and optimal security five principles. From feasibility of development mode, "tourism and sports", and "sports and tourism" these two types of development modes utilization values were higher. By far, Hanzhong city sports tourism resources were slower, mutual utilization between sports resources and tourism resources were not coordinate and lacked of sports tourism management professionals. Combined with Hanzhong practical status, author presented "tourism and sports" mode should be the main mode that adopts. On the premise that the mode went on smoothly, relying on resources advantages to carry out multiple modes' development. Such as, natural sightseeing tour and outdoors sports mode, agricultural sightseeing vacation and "farm work" mode, historical cultural sightseeing and "sports" mode. These modes played certain guiding roles in improving Hanzhong sports tourism status, and meanwhile provided references for relevant areas [4].

In 2013, Wang Yu-Zhen in the article "Chinese sports tourism industry competitiveness research", she applied Delphi and others multiple research methods to go deeper into study Chinese sports tourism competitiveness

a Corresponding author: tiyuxi@qq.com 
problems [2, 3]. Research results showed that main factors affected sports tourism industry competitiveness were production factors, market demands, correlation industries, enterprises competition and government behaviors. The author pointed out that Chinese sports tourism industrial competitiveness had structural model, which was composed of market demands, correlation industries supporting forces, production factors supplying forces, government regulation power and enterprise competitiveness. Among them, government regulation power occupied the largest proportion in the influence level.

\section{Model establishment}

\subsection{Data collection}

Table 1's data is from the article "Chinese high-end sports tourism theory and empirical research".

Table1. Status about amount of ski resort population and ski resorts.

\begin{tabular}{ccc}
\hline Year & Ski resort & Person-time (Ten thousand) \\
\hline 1995 & 9 & \\
1996 & 11 & 1 \\
1997 & 14 & 1.5 \\
1998 & 17 & 3 \\
1999 & 20 & 10 \\
2000 & 50 & 30 \\
2001 & 95 & 75 \\
2002 & 150 & 200 \\
2003 & 187 & 280 \\
2004 & 201 & 350 \\
2005 & 239 & 400 \\
2006 & 289 & 500 \\
\hline
\end{tabular}

Draw Table 1's data into broken line Figures 1-2, which can roughly show changes of recent ten years' amount of ski resorts and people that participate in ski.

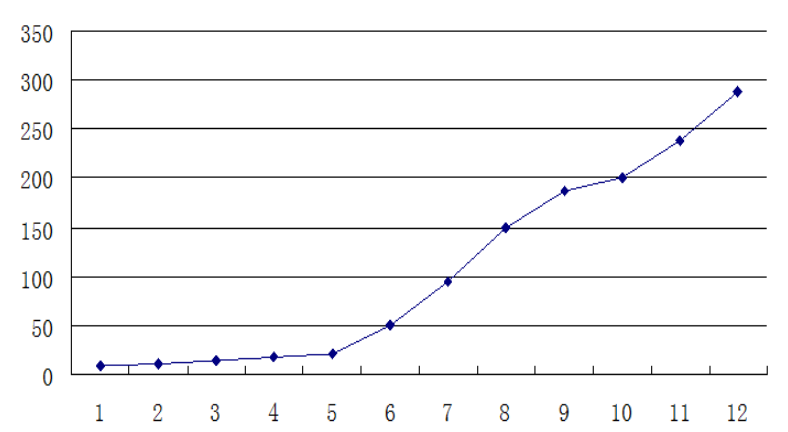

Figure 1. Change in the number of ski slopes.

Figure 1 is ski resorts amount change figure. In figure, mark "1 to 12 " respectively corresponds to year 1995 to 2006, from Figure 1, we can see that amount of ski resorts are gradually increasing.

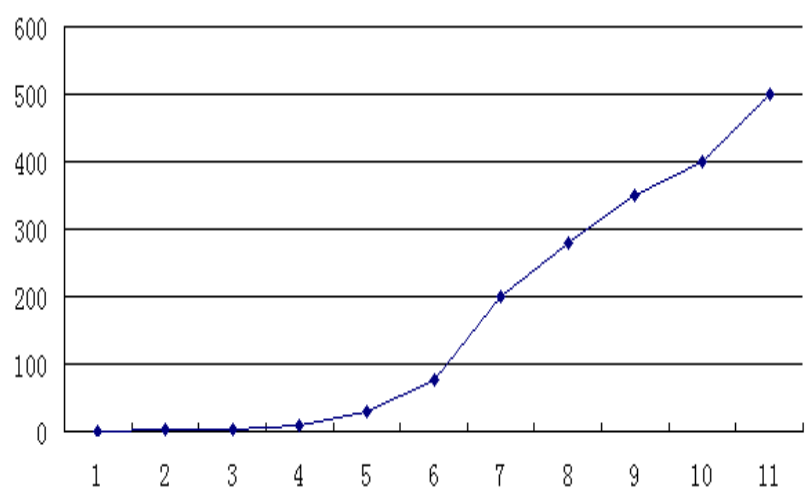

Figure 2. Changes in the number of skiing participants.

Figure 2 is amount of people that participate in ski. In figure, mark "1 to 11 " respectively corresponds to year 1996 to 2006, from Figure 2, we can see that number of people that participate in ski is gradually increasing.

\subsection{Grey model}

Grey system $G M(1,1)$ model is according to known lots of data, ranking these data according to time, fitting according to differential equations to draw near time sequence described dynamic process, by parity of reasoning, arriving at prediction target value. Such fitting method obtained model is time sequence one order differential equation [5]. Compare predicted results with real results as Figure 3 shows.

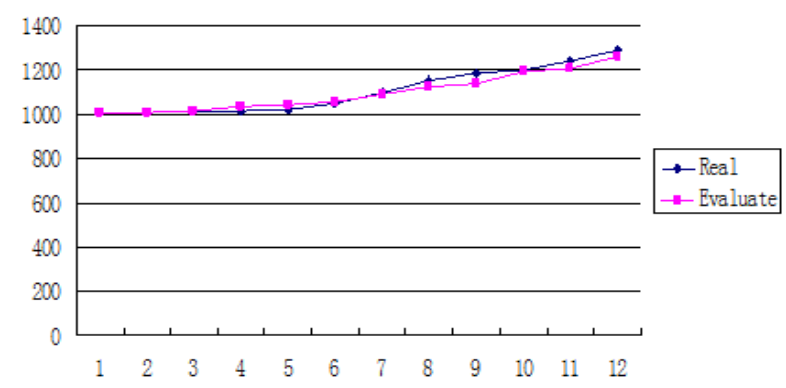

Figure 3. Comparison chart of the real and predicted values.

From Figure 3, we can see that drawing broken line from predicted results and real results are basically consistent, therefore, predicted results had reasonability.

\section{Conclusion}

Due to grey model owned convenience, good usability, it is widely used in multiple fields, solves relevant problems, and makes progress in agriculture, biology, weather and other fields. The paper applies grey model into predicting Chinese sports tourism development status, takes ski resorts development as an example to reflect Chinese sports tourism market development status. The paper makes prediction from ski resorts amount and ski participants amount two aspects, respectively makes prediction on ski resorts amount and the event participants amount according to algorithm steps and through Matlab software [6], by relevant testing, obtained models have reasonability. 


\section{Acknowledgments}

This research was supported by State general administration of sports philosophy and social sciences research project: based on "Internet + " the sport and tourism integration development path of research (project number: 2322SS16059).

\section{References}

1. B. Liu, S.L. Hu, H.X. Xu, J.H. Gao, Chinese Journal of Health Policy. 2, 13-17 (2009).
2. D.C. Zhang, M. Li, China Sport Science. 33, 3-23 (2013).

3. J. Zhang, Y. Wu, Journal of Shanghai Physical Education Institute. 80-82 (2012).

4. Y. He, M. Xu, Journal of Chengdu Physical Education Institute. 33, 43-45 (2007).

5. W. Chen, Z. Yang, W. Pan, Journal of Coastal Research. 73, 797-804 (2015).

6. J.H. Tang, K.Y. Wang, S.Y. Bei, M.M. Sousa, Journal of Mechanical Engineering Research and Developments. 39, 373-386 (2016). 